\title{
O CONSERVADORISMO COMO VIA PARA A MODERNIDADE
}

\author{
Francisco Carlos Teixeira da Silva*
}

\begin{abstract}
RESUMO:
O artigo pretende umi revisão do conceito de conservadorismo, em especial negar a visăo dominaste, sargida com Karl Mannheim. do conservadorismo enquanto ideologia reativa, anti-ficionalista cherança de uma sociedade de Antigo Regime. Pretende-se, assim, destacar o papel do conservadorismo como uma das vias de formaçío da modemidade e conforne suas exigâncias lécnicns.
\end{abstract}

Foi CHATEAUBRIAND quem cunhou, com seu sentido político atual, a expressão conservador: procurava, então, definir una postura militante, e para ele positiva, de reação clerical e política às consequências da Revolução Francesa.

Seu uso, já nos anos iniciais de 1830, ganlıou expressăo universal, com largo sucesso na Inglaterra e na Alemanha. Ao mesmo tempo, quanto mais se alargava o emprego da noçẫo, e com isso o cspectro de idéias, posturas e comportamentos que encobria, mais indefinida e vaga se constituia enquanto conceito. Assim, surgia uma forte tensão entre a prática politica, dita conservadora, co conceito de conservadorismo, como viria a ser operado nas nascentes ciências sociais.

Em face a tal indiferenciação Karl MANNHEIM debruçou-se sobre a questấo através de um artigo, escrito em 1927, que torna-se-ia uma referência obrigatória e até os nossos dias - para o bem e para o mal - não superado'. A preocupaçāo central de MANNIHEIM era estabelecer as bases teóricas de como operava o pensamento conservador, superando de vez a ambiguidade, e amplidão, indevida do termo.

MANNHEIM parte de uma postura teórico-metodológica explícita,

* Professor Titular de Histsria Modema e Contemporitnea TEMPO/FCSUFE, Para contatos c interciunbio E-Mail: Tempo (a) ifus.ufrj.br.

artios 9.9. Porto Alegre, n,6, dezenbro de 1996 
utilizando o conservadorismo enquanto objeto-piloto de sua análise. Tal comportamento inscreve-se com clareza no programa de trabalho por ele desenvolvido e direcionado para a sociologia do conhecimento, obrigando-o previamente a definir e discutir os critérios de sua análise. Antes mesmo de se constituir em un texto clássico sobre o pensamento conservador, o texto de MANNHEIM é um marco na História das Idéias?.

Partindo de un suposto estilo de pensamento, ou seja, grandes formações que crescem, se desenvolvem, fundem-se e/ou desaparecem - procurava historicizar as idćias, ou na expressäo original, die geistige Gebilde, as formaçốes espirituais. Mas, as idéias nĩo eram algo em si, auto-cxplicáveis:

"... a chave para a compreensăo das mudanças nas idéias deve ser encontrada nas circunstâncias sociais em mudanç, principalmente no destino dos grupos ou classes sociais que são portadores / traeger] desses estilos de pensamenio

MANNHEIN inscria-se, assim, decididamente numa vasta tradição intelectual alemā, entāo com cem anos de existência, de buscar no contexto as explicaçōes necessárias para a compreensão de um estilo de pensamento. Muitas vezes chegara a um verdadeiro paralelismo entre pensamento $\mathrm{c}$ vida social, observando que o destino dos grupos sociais está refletido claramente nas menores mudanças que se dão cm um estilo de pensamento ${ }^{4}$.

Utilizando tal análise "sociológica" do pensanento, MANNHEIM propōe uma abordagem histórica das circunstâncias sociais, do surgimento do conservadorismo. Para ele, o conservadorismo surgirá, assim, como uma ideologia defensiva face aos sucessos desintegradores [da antiga socicdade] provocados pela Revolução Francesa, retomando a tradição de Edmund BURKE. Assim, o conservadorismo é a contraproposta das "idéias de 1789":

"...sob a pressão ideológica da Revolugăo Francesa se desenvolveu na Alemanha um contra-movimento intelectual que reteve seu carater puramente intelecual por um longo periodo e assim foi capaz de desenvolver suas premissas de forma a mais extensa possivels.

Definia-se, desta forma, o conservadorismo como uma ideologia reativa e, ao mesmo tempo, a Alemanha como o topos privilegiado para sua análise.

O conteńdo ideático do conservadorismo seria, assim, definido por oposiçāo à matriz das "Idéias de 1789 ". Tratava-se, pois, de uma reaçấo ao lluminismo, entendido aqui como a representação intelectual do capitalismo burgués's. Ora, a AUFKLAERUNG, a Iluminação, havia erguido como temas básicos de sua argumentaçāo um corpo de idéias bastante caracterizadas, como

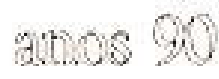


a doutrina do estado de natureza, o contrato social, a decorrente soberania popular e a existência inalienável de direitos do homem (ả vida, ả propriedade, à liberade, à felicidade, etc...). En suma, a argumentaçâo iluminista se concentra en torno da origem, extensão e características do pacto social, residindo aí, de um lado, a origem da Teoria Social moderna (MONTESQUIEU, LOCKE, ROUSSEAU) e, de outro, do pensamento politico moderno ( Liberalismo, Socialismo e Comunismo ).

Enquanto contra-movimento o conservadorismo deveria produzir uma explicaç̄̄o inversa, conn uma teoria social anti-contratualista, e um pensamento politico consequentemente anti-igualitário.

Para MANNHEIM o cerne do pensamento conservador se agrupa em torno dos seguintes pontos: (i) a descrença na Razĩo como guia e metro da experiência humana. o que levaria a uma profunda desconfiança em relação a qualquer abstração ahisłórica c (ii) a compreensĩo da sociedade enquanto um organismo vivo, cnraizado mum solo e sob un céu - como cra alirmado na cara expressão do romantismo alemão -, o que impossibilitaria a transferência de experiências históricas. Recusava-se, ainda. e em decorrência dos dois supostos anteriores, o atomismo social - base da visão liberal ( de acordo con a crítica anti-liberal) da sociedade como uma reuniỗo de indivíduos - e a cxistência de direitos naturais, posto que estes cstariam determinados pela experiência e pela tradição, năo existindo, desta forma, nada de natural ou a priori no Dircito dos Homens,

De unt ponto de vista geral, como uma grande aproximação, o estilo conservador de MANNHEIM descreve bem o que tradicionalmente chamamos de conservadorismo. Entretanto, quando nos aproximamos mais detalhadamente das fontes consideradas pelo autor instaura-se uma certa perplexidade. Os autores citados, como formuladores de um pensamento conservador na primeira metade do sćculo XIX na Alemanha, como HEGEL, MUELLER, STAHL. MÖSER c RANKE, apresentam tantas e tamanhas diferenciaçōes entre si que somos levados a nos questionar sobre de $\mathrm{tm}$ conservadorismo?

O próprio MANNHEIM, argutamente, percebe a dificuldade, que é, entấ, rapidamente debitada à dinâunica social, o que deveria reforçar seus pressupostos contextualizantes da idéia de estilo cle pensamento. Mas, a própria melodologia proposta, com sua aprecnsão histórico-sociológica, depõe contra tal explicação. particularmente, a questão se complexifica quando se introduz, ao longo do ensaio, o conceito de Direita, enquanto sinonímia de conservadorismo ${ }^{3}$. Neste sentido, o próprio autor trata de diferenciar do conservadorismo, seu tema básico, um tradicionalismo.

Enquanto o conservadorismo expressaria circunstâncias sociais

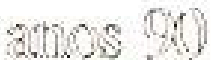


historicamente definidas, o tradicionalismo, retomando uma análise de WEBER, seria a cxpressão de um comportamento natural, instintivo e psicológico. Assim, não seria de admirar encontrarmos tradicionalistas de Direita e de Esquerda ${ }^{q}$. Ocorre que, nos textos básicos formuladores do pensamento conservador, com BURKE à frente, tradição assume um papel bastante especifico e, mesmo, fundamental para a compreensão do conservadorismo. Assim, as fantasias medievais de MÖSER ou HALLER dificilmente poderiam ser comparáveis ao clogio do sistcma britânico de governo feita por BURKE ou RANKE. Particularmente grave é uma certa confusão, já num texto posterior de MANNHEIM, entre as propostas regressistas (em direção a uma sociedade de Ancien Régime ou, ainda mais complicado, a uma sociedade de caráter estamental e corporativo ainda anterior ao Absolutismo) de cunho religioso e abertamente clericalistas, como nos irmãos SCHLEGEL c GERLACH. Grande parte do conteúdo de tais proposiçốcs, extremamente populares nas áreas católicas da germanidade ( como a Baviera e a Áustria) irá influenciar fortemente as formulaçóes, no final do século XIX. de uma doutrina social da Igreja.

O conjunto de tais posiçöes reunido numa só nubrica de conservadorismo cria mais confusão do esclarecimento, trazendo o risco de um retorno a um momento em que o conservadorismo, para alén de categoria das ciências politicas, impunha-se como frente única politica de reação face às ldélas de 1789 .

Ao mesmo tempo, MANNHEIM afirma a impossibilidade, enquanto ideologia reativa, do conservadorismo gerar sua própria utopia. Contrariamente ao liberalismo e ao socialismo, ambos formuladores de utopias perfeitas e, consequentemente, do fiu da História, o conservadorismo se definiria como o pensamento satisfeito com o aqui e o agora ${ }^{10}$. Ao conservadorismo cabia a defesa da socicdade existentc, com a qual se declarava solidário, o que portanto eliminava a possibilidade da construção de grandes sistemas utópicos que apontassem para um futuro melhor.

Na mesma linha de raciocinio caminharia Robert NISBET, onde tais questóces surgem ainda mais empobrecidas ${ }^{11}$.

Ora, os mesmos autores paradigmaticamente analisados, como por exemplo Justus MÖESER, trabalhaun claramente com a noção de fantasia que, aliás, é o nome de uma das obras mais importantes do periodo. As visões, no mais das vezes "inspiradas", da Idade Média - com a idealização, de um lado, de uma sociedade estamental, organizado corporativamente e sem lutas de classes (vetor anti-socialista ) e, de outro lado, solidária e orgânica e sem a atomização e anomia do individuo (vetor anti-liberal) - não seriam utopias ? Poder-se-ia, sempre, argumentar que utopias ș̃o visóes de futuro, como o faz. 
MANNHEIM. Politicamente, de um ponto de vista hodierno, é assim. Historicamentc, năo. Na sua acepção original, com Thomas MORE, a utopia é um mundo paralelo, real e do tempo presente. Sua existência serve de contraponto exato para se falar de um presente e, reconhecidamente, as caracteristicas ideais da ilha de Utopia sĩo contrapostas ao que MORE considerava nefasto na ilha da Inglaterra.

A Ulopia com caráter de descrição da sociedade do futuro tornar-se-ia uma verdade inconteste com a caracterização feita por K arl MARX do pensamento social de SAINT-SIMON, FOURIER e OWEN ${ }^{12}$. Mesmo ai, MARX nẫo cosenguirá operar uma cesura definitiva entre passado c futuro, posto que as utopias que descrevem a sociedade ideal sẫo todas, a seu ver, reacionárias:

"A literatura revolucionária que acompanhava esses primeiros movimentos do proletariado teve forçosamente um conteúdo reacionário

ou ainda

"Eis porque, se, en muitos aspectos os fundadores desses sistemas eram revolucionários, as seitas formadas por seus discipulos são sempre reacionárias, pois se aferram às velhas concepçoes de seus mestres..."

Em MARX, neste texto, reacionário, como veremos mais à frente, ligase a uma visão de clogio do passado cun termos de "Idade do Ouro", uma espécie de doença infantil das revoltas populares antes da organização da classe operária. Assim, aqueles que classicamente serviriam de paradigma para a construçầo das utopias. tinham no passado a matéria-prima de seus sonhos do futuro. A maioria dos estudiosos passaram a adotar (com, contra ou apesar de MARX) tal modelo de utopia. Assim, constituiu-se, inclusive em MANNHEIM, uma visão unilateral de utopia, de forma alguma amparada no que seria o modelo inicial, conforme o proposto por Thomas MORE.

Doravante Utopia referir-se-ia, exclusivamente, ao futuro. Se assim o for, e contra tudo o que argumentamos anteriormente, de fato o conservadorismo nẫo teria utopias. Estas residirian inequivocamente num tempo futuro, tuma terra do por-vir, transferindo para um amanlā, agora terreno, o reino da felicidae e da fartura.

Tanto MANNHEIM como NISBET, cntrctanto, concordan que o tempo conservador é outro que o tempo liberal. Enquanto o tempo aparece desmembrado, partido e atomizado no pensamento liberal, com vagas sucessivas que tomam seu sentido na relação com una idéia que terá sua certa e inexorável 
realização no tempo que se desprende de todos os outros tempos, representando o fim de sucessivos estados temporais: no pensamento conservador o entendimento do tempo só é possivel no momento em que percebe o passado que existe no presente, a aliança indestrutivel entre as épocas, numa sucessão infinitas e sempre atuais de jetztzeit, de tempos do agora. Desta forma, o futuro nada mais é do que o resultado da aliança entre mortos, vivos e não-nascidos ( para recuperarmos uma expressão de BURKE) e, nunca, um rompimento com o que ficou para trás ${ }^{\text {is }}$. Assim, a construção utópica do passado é um elemento fundamental da possibilidade do presente e única condiçấo de pensar o futuro. A questão torna-se, desta forma, tática: se renego devo necessariamente construir no futuro mas, se venero o passado, a única garantia do presente, é construí-lo à imagem da minha vontade sobre o passado. Neste sentido, as premissas de MANNHEIM/NISBET apresentam-se redutoras c, simultaneamente, contraditórias, posto insistir num tempo liberal diferente do tempo conservador (ou mesmo, de ver o tempo como liberal) e medir por este tempo liberal o sentido conservador de devir. NISBET insiste, em relação aos conservadores, na volta ao passado e nega, simultancamente, a possibilidade de construção teórica de uma viș̃o de mundo no interior do pensamento conservador:

"Os principios do conservadorismo flosófco trazem tô simplesmente um retorno aos postulados de tipo cosmológico-religiosos fundanentais da culura medieval"'.

Ora, que culfura medieval é esta? As fantasias de MÖSER e GOERRES, ou em escala curopéia, o universo de Walter SCOTT, HUGO ou HERCULANO? São exatamente estas obras que trazem um verdadeiro culto à Idade Média, uma idealização profunda e desprovida de qualquer apoio documental, de un mundo harmônico, guiado pela fé e pelo afeto, marcado por heróis pálidos, perdidos em bosques de plálanos e carvalhos, como nos quadros de Caspar David FRIEDRICH. Na Alemanha. HEINE mostrará claramente que o culto do gótico encobre um projeto político, de tipo estamental e aristocrático, simultaneamente anti-liberal e anti-absolutista. A Idade Média, com seus principios de ordem, autoridade c harmonia, surgia como uma utopia contrária à utopia liberal base e arsenal de onde se sacavam as armas para a luta contra a maré montante do liberalismo. Para esta corrente politica cabia reafirmar as autoridades locais, negar a construçăo de uma entidade alemã supra-regional, colocando-se claramente ao lado das pretensōes austrícas de manutenção de uma Alemanha de sábios e poctas, distante do projeto nacionalliberal, onde aparecia uma Alemanha de industriais e militares. Grande parte de tais idćias formara o futura arsenal do clericalismo e do conservadorismo 
ultramontano, na Áustria, na França e na própria Alemanha. Assim, de forma coerente a utopia conservadora é construída no passado, pois o futuro nada mais é do que o desdobrar da História.

Alguns poderiam argumentar que tratar-se-ia, no caso, bem mais de um mito - da sua construção - do que de uma utopia. A bem da verdade, são tais mitos da ldade do Ouro Perdida que informan as utopias, mesmo as progressistas. Scria possível a construção da sociedade sem classes no futuro sem a idéia da sociedade sem classes - a comuna primitiva - no passado ?

Tais questōes levam, nccessariamente, a um outro ponto recorrente na análise do pensamento conscrvador: a questão do papel atribuido ao passado. NISBET afirma que o objetivo último do conservadorismo seria a anexaçäo dos dogmas religiosos ao poder temporal do Eslado e, necessariamentc, a instauraçẫo de uma teocracia ${ }^{17}$. Ora. a quem se referem tais assertivas? De forma alguma ao conservadorismo britânico do final do século XVIII e começo do XIX, absolutamente laicicizado, senhor de una releigiåo de Estado mecânica e exteriorizada consubstanciada na Igrẹa Anglicana; também nĭo serviria para HEGEL, caracterizado como conservador, e muito menos para RANKE. Para os ingleses cra evidente que o universo havia sido dessacralizado e a questāo religiosa se apresentava com o pudor do bom-lom. Para HEGEL e RANKE a questảo principal residiria numa retomada de MAQUIAVEL, controlada e temperada na tradição. Quem ș̃o. então, os couservadores de NISBET e MANNHEIM? As citaçóes recaem cm DE MAISTRE, BONALD e STAHL, Aqui chegamos a um ponto fundamental: a necessidade de diferenciaçăo no interior do chamado conservadorismo.

VON DER GABLENTZ embora concordando com MANNHEIM, que somente ao ser questionada coube à ordem uma racionalização conservadora, procurava avançar a questão. Distingue, entĩo, ao menos, três situações diversas tho conservadorismo: legitimistas restauradores, reformistas conservadores e reacinários ${ }^{18}$.

Na análise de VON DER GABLENTZ, largamente tributária da obra do historiador austriaco RITTER VON SRBIK, os legitimistas aparecem divididos en dois grupos: legitimistas insitucionais e legitimistas feudalizantes. Os primeiros cram defensores da ordem anterior a 1789 , propunham a continuidade institucional e dinástica e. como tal, descmpenham um papel chave no Congresso de Viena; já os últimos propunham um recuo maior, com o retorno à situação anterior à princira "revoluçāo": anterior ao Estado Absoluto de feição iluminista. Considerava-se, aqui, as próprias dinastias legitimas, anteriores a Napoleão. como usurpadores, no sentido de terem assumido os programas reformistas dos filósofos, ou seja, do Iluminismo. A legitimitade residiria na tradição corporativa-estamental anterior ao Despotisno Esclarecido. 
Tais conservadores formarào no plano estético, filosófico $\mathrm{e}$ histórico, ao lado dos românticos regressistas, defensores de uma Idade Média idealizada em torno das noções estamentais de Estado. HALLER, MÖSER, GOERRES, os GERLACH serão grandes nomes desta corrente. De qualquer forma, ambas as correntes estão unidas politica e filosoficamente na recusa ao racionalismo iluminista e a qualquer forma de constitucionalismo, posto que o Estado se funda sobre a ação de grandes personalidades. Em seu conjunto poder-se-ia falar de restauradores, já que alınejavam o restabelecimento de formas sociais c politicas que não mais existiam. Devemos destacra, com precisão, a forte componente católica no interior desta corrente, em especial no anscio por uma restauração de uma cristandade estamental e agrária.

O conservadorismo reformista ligava-se, por sua vez, claramente à ação da monarquia absoluta, ao ideal de um Estado munido dos meios e da capacidade de conduzir a sociedade, sem a ditadura da burocracia e sem a ditadura da soberania popular. Um modelo intermediário, paternalista, e de dificil observação histórica ${ }^{15}$. Por fum, a Reação, caracterizada pelo oportunismo da classe dirigente ( nẫo se fala cm classe dominante) e do seu temor face à qualquer mudanca:

"O reacionário não tem nenhuma relaçăo com a História. Do seu desenvolvimento nada the interessa. Mas, ele não deve também se entusiasmar pelo passado. $A$ ordem existente nöo deve ser periubada, pois é, ao menos, ordem. Ela serve aos interesses dos poderosos e justifica esses mesmos interesses, que correspondem à ordem e ao equilibrio. Movimento é sempre suspeito, pois fundamentalmente é desordem (Unordnung). O reacionaro vive no presente e teme todo movimento, inclusive a Restauraçăo " ?o

Ora, tal análisc, por major que scja o mérito de buscar uma certa historicidade, acaba por dissolver seu objeto. Enquanto para MANNHEIM/ NISBET todos são conservadores, para GABLENTZ, na prática, ninguém é conservador"?

Com o risco de chantar o diabo para rezar a missa poderiamos dizer, com Alan de BENDIST - o chefe de fila da Nova Direita francesa -, que se permitiu o domínio dos mitos incapacitantes, através dos quais se engloba sob o mesmo rótulo as mais diferentes tendências de pensamento ${ }^{n}$.

Se, as diferenciaçōes propostas por GABLENTZ padecen de incorrigivel artificialismo, a iniciativa é, $\mathrm{cm}$ si, louvável, Jă MARX, diferenciando correntes politicas e intelectuais, havia distinguido entre conservadorismo e reacionarismo. 
MARX vincula o reacionarismo com a aristocracia feudal, batida pela burguesia em ascensão, e incapaz de travar uma huta politica séria-dai, travarem sua guerra perdida no domínio literário:

"Se por vezes, a sua critica amarga, mordaz e espirituosa feriu a burguesia no coraçāo, sua impotência absoluta de compreender a marcha da historia moderna terminou sempre por um efeito cómico"z.

Neste grupo, como reacionários, incluiam-se os legitimistas franceses, restauradores alemăes e certa intelectualidade inglesa reunida em torno de Thomas CARLYLE. Indo mais além, MARX lembra que o processo de modernização não isolou apenas a aristocracia fundiária. A pequena burguesia e o campesinato constiluiam-se $\mathrm{cm}$ fração complementar da sociedade burguesa que se reconstitui incessantemente ${ }^{2 t}$. Face a cxpansão capitalista vêem-se isolados c condenados, reagindo com acrimônia ao novo. Assim, esperam reslabelecer as antigas relaçóes de propriedades $e$ foda a sociedade antiga, ou, bem ao contrário, forçar o novo a conformar-se às antigas relaçôes de propricdade:

"Num e noutro caso, esse socialismo é ao mesmo tempo reacionário e utópico ${ }^{35}$

De qualquer forma o alvo principal da luta de ambos os segmentos reacionários, o aristocrático e o popular, é a modernização burgucsa.

Conservadorismo, por sua vez, é visto como uma forma de pensamento moderno e, malgrado a antipalia devotada ao mesmo por MARX, pensamento implicado com o progresso:

"Querem a sociedade atual, mas eliminando os elementos que a revolucionam e a disssolvem. Queren a burguesia sem proletariado. Como é natural, a burzuesia concebe o mundo en que domina como o melhor dos mundos "s

Ora, estamos aqui face a dois procedimentos interessantes: (i.) a diferenciaçăo operacional dos conceitos conservador e reacionário e (ii.) o deslocar do pensamento conservador para o campo da modernidade, bem ao contrário do procedimento de inúmeros criticos liberais do século $\mathrm{XX}$. Evidentemente, c para um certo desconforto de MARX, o liberalismo deslocavase simetricancute mais à esquerda, o que cra, enfim, real nos anos de $1847 \mathrm{c}$ 1848.

MARX năo está só ná caracterização do conservadorisno como um




pensamento inscrito na modernidade. W. RIBHEGGE, cientista político alemão, caracteriza o conservadorismo como veriente política burguesa, tanto em 1848 como cm 1918 27 . Da mesma forma, o historiador M. VALJAVEC reage contra a caracıcrizaçăo do conservadorismo como uma ideologia reativa, criada em função da Revolução Francesa. VALJAVEC concebe o conservadorismo como uma força ativa, já em ação em pleno século XVIII, contrapondo-se ao Iluminismo de cunho materialista e radical. Assim, poder-se-ia falar em um "Iluminismo conservador" 28 .

A relaçĩo entre o Iluminismo e o Conservadorismo já fora destacado, en artigo pioneiro de 1912, por Adalbert WAHL. Dedicando-se a análise da obra de MONTESQUIEU, WAHL mostra como a relação entre Direito, condiçōes naturais ("o clima e o céu") c a tradição são elementos fundamentais na constituição dos regimes políticos. Da mesma forma, tais especificidades desaconsclhariam qualquer tentativa de imposição de regimes, devendo-se pois, respeitar a originalidade dos povos, que emprestam seu espirito aos regimes sob os quais vivem ${ }^{24}$.

Samuel HUNTINGTON nos apresenta uma proposta interpretativa próxima quando, por exemplo, nos fala em um conservadorisno já no século XVII. Ai, na luta contra o avanço da centralização absolutista, muito antes do liberalisuno problematizar o Estado. estariam as origens do pensamento conservador. Trata-se de unta formulação pluralista-medieval, com seu fulcro nos corpos intermediários da sociedade, como as corporaçôes e as cidades. MONTESQUIEU teria captado largamente tal movimento e centraria a defesa dos Parlements provinciais na importância dos corpos intermediários ${ }^{* 0}$ e como tum antidoto aos excessos da centralização monárquica. Assim, a crítica de MONTESQUIEU ao absolutismo fundamentaria muito mais o nascente pensamento conservador do que constituir-se-ia em pilar do liberalismo.

A questāo aqui cxistente seria evitar uma caracterização muito forçada das oposiçốes cxistentes entre Iluminismo/Conservadorismo - compreendendo este último seu vićs romântico e historicista. É assim que Steve SEIDMAN observa a tentativa monopolista de liberais, do século XIX e do sćculo XX, em opor às Luzes tudo que não se inscrevesse claramente no seu ideário ${ }^{31}, O$ Ilumuinismo seria necessariamente racionalista, abstrato, sintético c progressista. Ao mesmo tempo. dá-se um gigantesco esforço em identificar os críticos do racionalismo abstrato - $\mathrm{e}$, note bene năo necessariamente de todo o Iluminismo - com o anti-progresso, com as continuidades imóveis e, então, com uma história nolurna e pessimista. Ora. os principais pensadores do inicio do século XIX como BURKE, RANKE e HEGEL - se, não säo devedores da ideologia do progresso, são, por seus métodos, racionalistas. criticos c apontam claramente para uma História em movimento. $O$ desconcerto em insistir em tais dicotomias

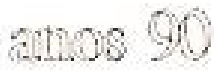


absolutas levará BAUMER a falar em um neo-iluminismo na primeira metade especial a linguagem do racionalis autores ${ }^{32}$. Os métodos das Luzes, $\mathrm{cm}$ aprofundamento da Hermenêutica - nos - com a crítica aos textos c o único ou monolítico. Em larga escala, a mostram que o Iluminismo não era contra a imposição đa ideologia do prograçăo romântica e historicista é dirigida conteúdo da idéia de progresso, contresso, ou, ao menos, a um determinado progresso não abre uá gresso, contudo en sua crítica à própria noção de fundamentada num RANKE à crítica do texto, cabentica iluminista. Não é gartuito o apego de enquanto método de estudo,

progresso fraternidade burguesa e do movimento linear $\mathrm{cm}$ direçầo ás idéias da veementemente por rounânticos e historicistas. Oragulável, será recusado ser redızido a idéia de progresso? São os que pera todo o Iluminismo poderia forma, unilateral a filiaço ao llum os que pensam assim que promovem, de comunismo, como as íca ao lluminismo do liberalismo, do socialismo c do seria, não só oposição. como estaria, da modernidade. O conservadorismo negra iluminando uma História noturna. origens do totalitarismo, esquecendo-se que no não hesitarăo em buscar aí as da Prússia, ou no Staatspolizei de Luís XIV no Estado-máquina de Frederico do Estado invadiant as dimeñó

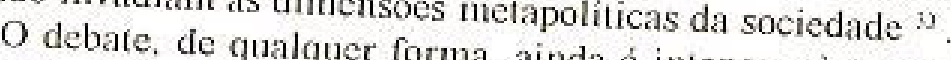

dicotomia radical aliam-serma, ainda é intenso: à tese 1radicional, da BRUNSCHWEIG com lado, não só pensando continda noçăo de trahison des clercs; do outro fundamentalmente numa filiaçâo Gudades, em especial de métodos, mas, voltar a ler *. DILTHEY, MEINECKE, Periamos CASSIRER - que deveríamos especial, toda bordada de detalhes e va, Peter GAY e SEIDMAN. Numa posição Paul HAZARD.

Malgrado as diferenças, e elas existem, estaríamos repondo no corpo da tradição do Ocidente, as grandes correntes de pensamento vinculadas por continuidades e oposiçōes ao Iluminismo, como nas antinomias de DILTHE $Y^{t 4}$.

Assim, MONTESQUIEU poderia facilmente ser apropriado por liberais e historicistas; VOLTAIRE emprestaria o método crítico ả historiadores liberais e conservadores c ao ROUSSEAU do CONTRATO SOCIAL poder-Sc-ia sempre DESIGUALDADE, ponto de inspirCURSO SOBRE A ORIGEM DA nada devedor neste contexto de HERDER uma História original dos povos, e

Em especial, a presença de MONTESQUIEU recobre as fontes do

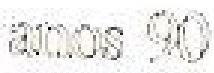


pensamento conservador, marcando uma oposição nítida ao Estado-Máquina provido da filosofia iluminada - numa época em que a burguesia ainda nẵo era oposição. Neste sentido, a exigência de uma partilha, pela sociedade, dos atributos da soberania é uma exigência comum. Para os conservadores, bem ao contrário do liberalismo, terá um significado muito particular, Günther BARUDIO dirá que o objetivo de tal movimento era a defesa das Libertäre Verfassunge, as constituiçổes libertárias de origem medieval ${ }^{5 s}$. Liberdade, aqui, cra a expressão da conservação dos privilégios, leia-se autonomias, dos corpos estamentais face ao avanço da autoridade régia. Neste sentido, é importante marcar a origem e conteúdo diferenciado do conceito liberdade. Enquanto no pensamento liberal refere-se à esfera de ação do indivíduo, no pensamento conservador liberdade é concebida como a garantia da autonomia dos diversos corpos sociais, no interior dos quais - e, só ai - os individuos se qualificam. Fora de tais corpos nâo há liberdade, posto que a atomizaçăo do individuo é a desordem.

Kurt VON RAUMER utilizando-se recursos do idioma alemāo contrapöe uma Korporative Libertät a uma Persönliche Freiheit, como forma de evidenciar as diferenças.

Efetivamente, tanto com MONTESQUIEU como com HERDER, deuse uma leitura liberal, onde a doutrina da partilla dos poderes ou do Estado sem povo, com seu caráter anti-absolutista cram encaradas como naturalmente liberais. Assim, todo contcúdo libertário-estamental é esvaziado em favor de um doutrina do Estado, cujas bases serviriam também ao conservadorismo ${ }^{36}$. Neste sentido - c aqui podemos buscar a motivação de MARX em deslocar o conservadorismo para o campo dea modernidade - nāo se poderia falar em ideologia reativa, em especial face à Revolução Francesa. Liquidada a fatura feudal - isso já en agosto de 1789 - a Revolução teria se constituido, para lá do entendimento ideológico-edificante, em um violento choque entre facçōes da própria burgucsia. Não se trala de una derrapage ou de una fase popular da Revolução. Os diversos projetos intentados e as fases vividas resultariam do experimentalismo racionalista e abstrato, das lutas interburguesas. Assim, a Revolução Francesa nấo se explicaria nem por SOBOUL, nem por FURET e. sim, com BURKE. O conservadorismo não scria uma reaçăo feudal, antiburguesa à Revolução Francesa. Estaríamos face à uma reação das parcelas estabclecidas da própria burgucsia. Em BURKE, GENTZ ou RANKE não há nenhum desejo de retorno ao passado: quer-se a ordem presente, sem as contradições então vividas. Muitas das idéias geradas ainda no scio do Iluminismo serão retomadas e incorporadas. A argumentação já utilizada contra o absolutisno régio será alualizada contra o absolutisno do povo. Na expressão de BURKE, nem tirania do rei, nem tirania da massa. 
Evidentemente cxiste uma reaçăo à Revoluçăo Francesa: os que querem o passado, as dinastias, a aristocracia c os camponeses - reacionários, feudalizantes e legitimistas cnvolver-se-ão com o clericalismo militante, com a reconstrução da unidade do cristianismo, cuja a mclhor expressão (embora

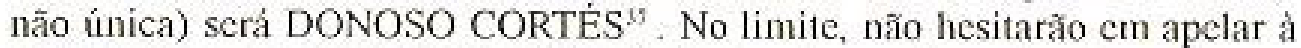
violência, ao golpe, e mesmo à Revoluçâo contra a ordem vigente, como na França da Terocira República ${ }^{\text {ss }}$. Ao contrário dos conservadores estarão fora do campo da modernidade. Os primeiros, por sua vez deverâo, com urgência, ser recuperados como um das vias da construção do mundo moderno.

Um retortio ao estudo do pensamento conservador afigura-se, hojc, como um procedimento fundamental. Num momento em que presenciamos a ressurgência do fascismo e, contraditoriamente, alguns afirmam com ênfase a indiferenciação dos campos políticos, devemos voltar-nos, com atenção, para as fontes de un rico filâo do pensamento moderno ${ }^{*}$. Para além de vestígio de uma outra época, anterior a 1789, ou meramente reação ao Iluminismo, podemos vislumbrar no conservadorismo um corpo tcórico arliculado, musculoso e seminal, capaz de combinar apego à técnica e sonhos românticos sobre uma Idade Média que nunca existiu; racionalidade tecnológica e os mais profundos preconceilos sociais ou raciais, descuhando contradiçōes que marcaram o século XX e aneaçam invadir o sćculo XXI.

\section{NOTAS E REFERENCIAS}

1. MANNHIIM, K. "Das Konservative Denkens": In: Archiv fuer Sozialwissenschaft, 57, H, 12. pp.68-[42, 1927 e IDEOLOGIA E UTOPLA. Rio de Janeiro, Zahar, 1968 (1929)

2. Ver REILL. H.F. The German Enlightenment and the Rise of Historicism. Berkley, The 1'niversitu Press. 1975.

3. MANNHEIM, K. "Das Konservative Denkens", op. cit., p. 78.

4. Idem, op. cit., p, 81 e BCTRKE. E. Reflectons on the Revolution in France. 1 ondres, J. Dodslev, the 5th. Ed., 1790.

5. MANNHEIM, op. cit.,p. 87.

6. ldem, op cit., p. 95 .

7. Ver ETSTEIN, K. The Genesis of German Conservatism. Princeton, The University Press, 1966.

8. $\quad 1 \mathrm{dem}$, op cit., p. 97 .

9. ldem, op cit. pr. 100-102.

10. Idem, IDEOLOGIAE UTTOPIA.. Pp, 253-254

11. NISBIIT, Robert. TRADITION AND REVOLT. New York, Vintage Books, 1970, p. 121.

12. MARX, Karl. DAS MANIFEST DER KOMLNISTISCHEN PARTEL. Berlin, Marx-Eingels Institut, 1970, p. 45 .

13. [dem. p.44.

14. [dom, p.45.

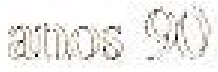


15. Para uma discussūo sobre o tempo e o devir ver HABERMAS, J.; Bewusstmachende oder rettende Kritik. Zur Aktualităt Walter Benjamins. In: Kultur und Kritik. Frankfurt am Main, 1973 , pp. 302-44.

16. NISBET, R. op. cit. p. 75

17. NISBET, R, Op, cit, pp, $75-76$

18. V.D. GABLENTZ, O. "Reaktion und Restaration" In; SCHUMANN, H.-G. KONSEVANTISMUS, Frankfurt, Kiepenheuer, 1974, p. 79.

19. V.D. GABLENTZ, Otto, Op. cit. p. 84.

20. V.D. GABLENTZ. Oto. Op, cit. p. 84.

21. V.D. GABLENTZ, Oto. Op. cit. p. 79.

22. BENOIST, Allan de. VU DE DROITE. Paris, Albin Michel, 1975, p. XXIV.

23. MARX, K. Op. cit. p. 38 .

24. [dem, op. cit. p, 40.

25. Idem, op, cit. p, 40.

26. Idem, op. cit. p., 43 .

27. RIBILEGGE. W. "Konservantismus. Versuch zu einer Kritisch-historischen Theorie" In: KONSERVANIISMUS, op. cit. p. 122.

28. VALJAVEC, E. "Dic Entstehung des europacischen konservativismus" In: KONSERVATISMUS, op. cit. p. 147.

29. WAHL A "MONTESQUIEU als Vrlaenfer von Aktion und Reaktion" ]n: H.Z, 1912, 109, pp. $129-148$.

30. HUNTINGTON, S. "Konservatismus als Ideologie" In: KONSERVATISMUS, op. cit, p. 93.

31. SEIDNAN, Steven. T.E 1,IBÉRAIISME ET LA THEORIE SOCLALE EN EUROPE. Paris, PUF. 1987 (1983), pp. 20 e 21.

32. BAUMER, F. O Pensimento Modemo, Lisboa, Ed, 70, 1977, p, 30.

33. Para a discussâto do liberal ismo alemžo, seus limitese contradiçũes, ver GAJ_L, L. "Liberalismus 4. bürgerliche Gesellsthafl" In: H.Z, 220, 1975, pp. 324-357 e, na mesma revista, "Dic deutsche Liberalismus zwischen Revolution u. Reichsgründung". In: H.Z.. 228, 1979, pp), 98-108.

34. DILTHEY, Wilhem. TEORLA DAS CONCEPCYOES DO MUNDO lisboa, Ediçōes 70, 1992. em especial Parte 1I, pp. 107-160.

35. BARUDIO, Guenter. DAS ZEITALTER DES ABSOLUTISMUS UND DER AUFKLAERUNG. Frankfiart, Fischer, 1981.

36. VON RALMER, K. "Absoluter Staat, Korporitive Libertaet, persoenliche Freiheit" In: HOFMANN, H.H. DIE ENTSTEHLNG DES MODERNEN SOUVERAENEN STAATES, Frankfurt, Kiepenheuer, 1967, p. 173.

37. DONOSO CORTES, J. ENSAYO SOIBRE IEL CATOLICISMLO, EL LIBERALISMO Y EL SOCIALISMO. Buenos Aires, Anericalle, 1943 (1851).

38. LGLESIAS, Francisco. "Listudo sobre o pensamento reacionsírio: Jackson de Figueiredo". Revista Brasileira de Cièncias Sociais, V. II, $\mathrm{n}^{\circ} .2,1962$, pp. 3-52.

39. VEBLEN, Thorstein. "A Alcmanha Imperial e a Revoluçäo Industrial" In: Os Pensudores, Sĩo Paulo, Abril. 1974, pp. 265-276. 